\title{
A Silvicultura no INPA
}

\section{Niro Higuchi $(*)$}

\section{Resumo}

O presente relato procura mostrar a evolução da Silvicultura, em termos de pesquisas, durante os 27 anos de existência do Instituto Nacional de Pesquisas da Amazônia (INPA), desde a primeira proposição para a criação de uma reserva florestal pelo botânico Adolfo Ducke, atualmente Reserva Florestal Ducke, até os dias de hoje, sendo também referenciada ao desenvolvimento florestal no Brasil. São apresentados, resumidamente, os trabalhos de pesquisas silviculturais desenvolvidos e em desenvolvimento pelo Departamento de Silvicultura Tropical na Reserva Florestal Ducke (Km-26 da Rodovia Manaus-Itacoatiara com 10000 hectares) e na Estação Experimental de Silvicultura Tropical (Km-45 da Rodovia Manaus-Caracaraí com 21000 hectares). Sobre trabalhos em desenvolvimento, neste momento, a prioridade do Departamento de Silvicultura Tropical é o projeto Manejo Ecológico e Exploração da Floresta Tropical Umida, no Distrito Agropecuário da SUFRAMA (Superintendência da Zona Franca de Manaus), a partir do $\mathrm{Km}-14$ da vicinal ZF-2, com ênfase especial à Regeneração natural. Alguns dos trabalhos, com resultados conclusivos sobre aspectos silviculturais nas estações de pesquisa do INPA, foram listados no corpo do presente relato.

\section{HISTORICO}

O histórico da Silvicultura no INPA tem o seu início simultâneo com a fundação do Instituto em 1954 e, tem muito a ver com o processo de desenvolvimento da Política Florestal brasileira.

Em 1937, no Estado do Rio de Janeiro, é criado o primeiro Parque Florestal Nacional e, em 1944, a primeira Floresta Nacional em Capão Bonito no Estado de São Paulo.

Em 1954, o botânico Adolfo Ducke, um dos maiores nomes da Botânica na Amazônia, preocupado com a manutenção da cobertura florestal da região, sugere a criação de uma reserva florestal pelo INPA, o que hoje é a Reserva Florestal Ducke.

A portaria $n^{0} 34 / 56$, de 17 de Julho de 1956 , estrutura provisoriamente o Centro de Pesquisas Florestais do INPA que, por sua vez, no ano seguinte, propõe a criação da Seção de Silvicultura, objetivando organizar e fomentar a Silvicultura na região Amazônica. No projeto de criação, a Seção de Silvicultura tinha como finalidades: (a) fomentar a Silvicultura na Amazônia determinando áreas para reflorestamentos com espécies de madeira de lei, oleaginosas, gomíferas e outras; (b) contactar com as demais seções do Centro de Pesquisas Flo. restais como a Seção de Botânica, de Solos, de Fitopatologia e de Celulose; (c) contactar com outros órgãos de interesse à Seção de Silvicultura como o Setor de Zoologia (Seção de Entomologia) do INPA e outros Centros de Silvicultura brasileiros e estrangeiros.

No Estado do Pará, em Curuá-Una, a Superintendência do Plano de Valorização Econômicơ da Amazônia (SPVEA), hoje SUDAM, em convênio com a $F A O$, inicia as primeiras pesquisas florestais em 1958.

Em 1962, o Governo do Estado do Amazonas cede oficialmente 10.000 hectares de terras do Estado para o INPA, constituindo então a Reserva Florestal Ducke. Essa doação só é consolidada através da Lei $n^{0} 41$, de 16 de Fevereiro de 1963, publicada no Diário Oficial do Estado, não impedindo, entretanto, o início das atividades silviculturais em meados de 1960 , através da Seção de Silvicultura. Nesse ano foram delineadas as primeiras pesquisas florestais, começando com a preparação de terreno para plantios e instalações de viveiro e infraestrutura para suportar a pesquisa na reserva florestal.

Os primeiros plantios na Reserva Ducke datam de 1962, sendo intensificados nos anos seguintes, unicamente com espécies florestais nativas. Trabalhos com enriquecimento da floresta natural, estudos fenológicos, semente e viveiros também foram iniciados nesse período.

(*) - Instituto Nacional de Pesquisas da Amazônia, Manaus. 
Em 1965 é criado o Código Florestal brasileiro; em 1966 são introduzidos os incentivos fiscais para reflorestamento, principalmente para a região Sul do Brasil, e, finalmente, em 1967, é criado o Instituto Brasileiro de Desenvolvimento Florestal (IBDF), órgão incumbido do disciplinamento da Política Florestal a nível nacional.

No início da década passada, o INPA com nova orientação para a Reserva Florestal Ducke, fez a aquisição de 21.000 hectares de terras no Distrito Agropecuário da SUFRAMA. Todos os novos experimentos com plantios foram transferidos para a nova área de pesquisas florestais, a Estação Experimental de Silvicultura Tropical. Nessa área foram instalados, a partir de 1972, experimentos com regeneração artificial, enriquecimento da floresta natural, fenologia, sementes e viveiro.

A Reserva Florestal Ducke passou então à condição de reserva biológica, com o objetivo de servir de suporte para todos os segmentos da pesquisa do Instituto, mantendo somente os experimentos florestais existentes, conservando-os periodicamente.

Hoje a Estação Experimental de Silvicultura Tropical é a base física para todas as pesquisas florestais-do INPA que, após vários anos de ensaios de espécies, de eliminação, de espaçamento e outros, parte para um projeto de Manejo da Floresta Natural de Terra Firme, integrado com todos os demais departamentos do INPA. A implantação desse projeto iniciou efetivamente em 1980, no Km-22 da vicinal ZF-2. Do ponto de vista silvicultural esse projeto envolverá todos os setores da Ciência Florestal, ou seja, Exploração, Regeneração artificial, Regeneração natural, além das pesquisas de base como auto-ecologia, fisiologia, nutrição e outras.

A despeito do tempo que a Silvicultura tem participado da própria história do INPA, somente em 06/08/80 esta ganhou total independência dentro do esquema de organograma do Instituto, transformando-se em Departamento de Silvicultura Tropical.

\section{PESQUISAS REALIZADAS}

\section{RESERVA FLORESTAL DUCKE}

As pesquisas florestais na Reserva Ducke iniciaram-se com ensaio de espécies nativas, plantadas sob sombra e em plena abertura, a partir de 1963. Neste experimento foram envolvidas 20 espécies florestais, plantadas numa área de aproximadamente 30 hectares. Em 1970 teve início às medições dendrométricas para acompanhar o desenvolvimento dos povoamentos florestais implantados. Essas medições têm sido feitas anualmente com o objetivo de determinar o crescimento e incremento da floresta formada e dessa vale ressaltar o desenvolvimento das espécies como Carapa guianensis (Andiroba), Jacaranda paraensis (Caroba), Goupia glabra (Cupiúba), Bagassa guianensis (Tatajuba), Cedrelinga catenaeformis (Cedrorana), Scleronema micranthum (Cardeiro) e Callophyllum angulare (Jacareú. ba)

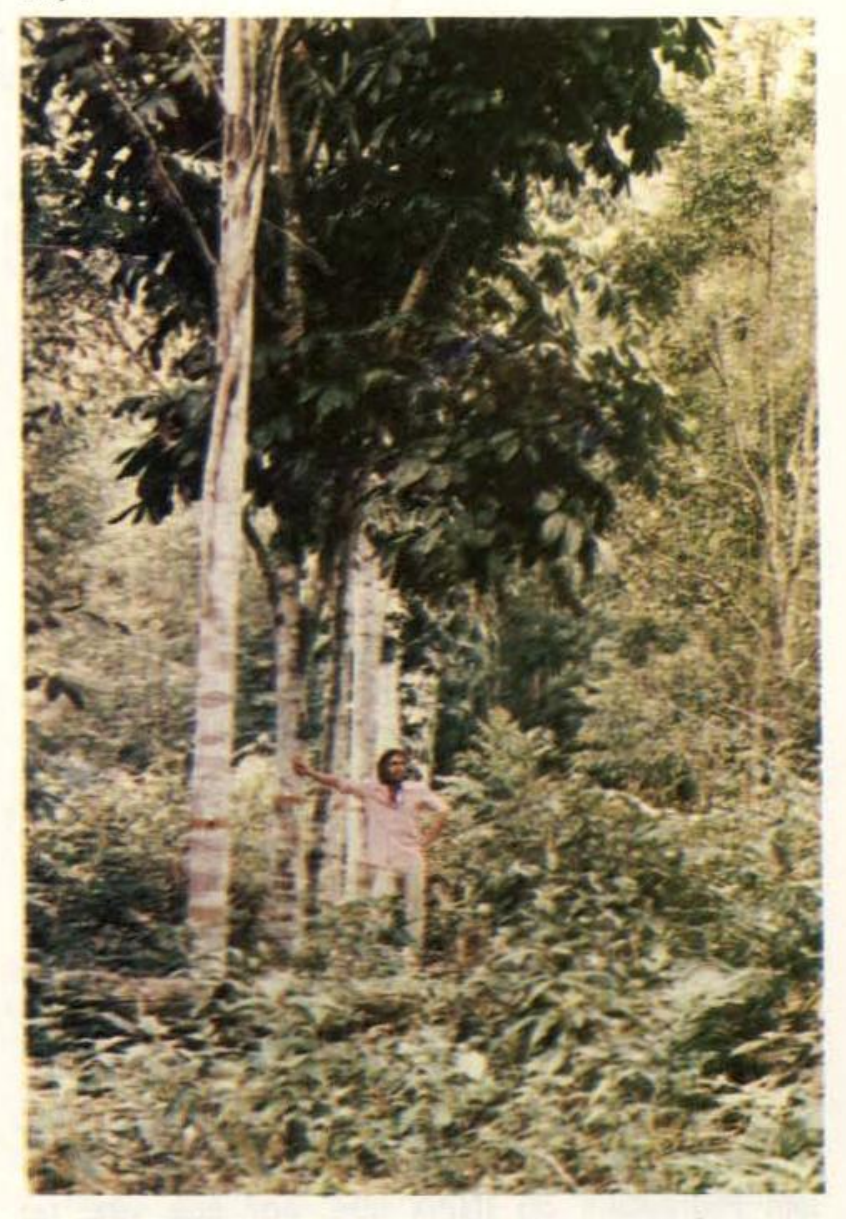

Fig. 1 - Primeiro plantio de Carapa guianensis na "Reserva Ducke", 4 ni 1964. 


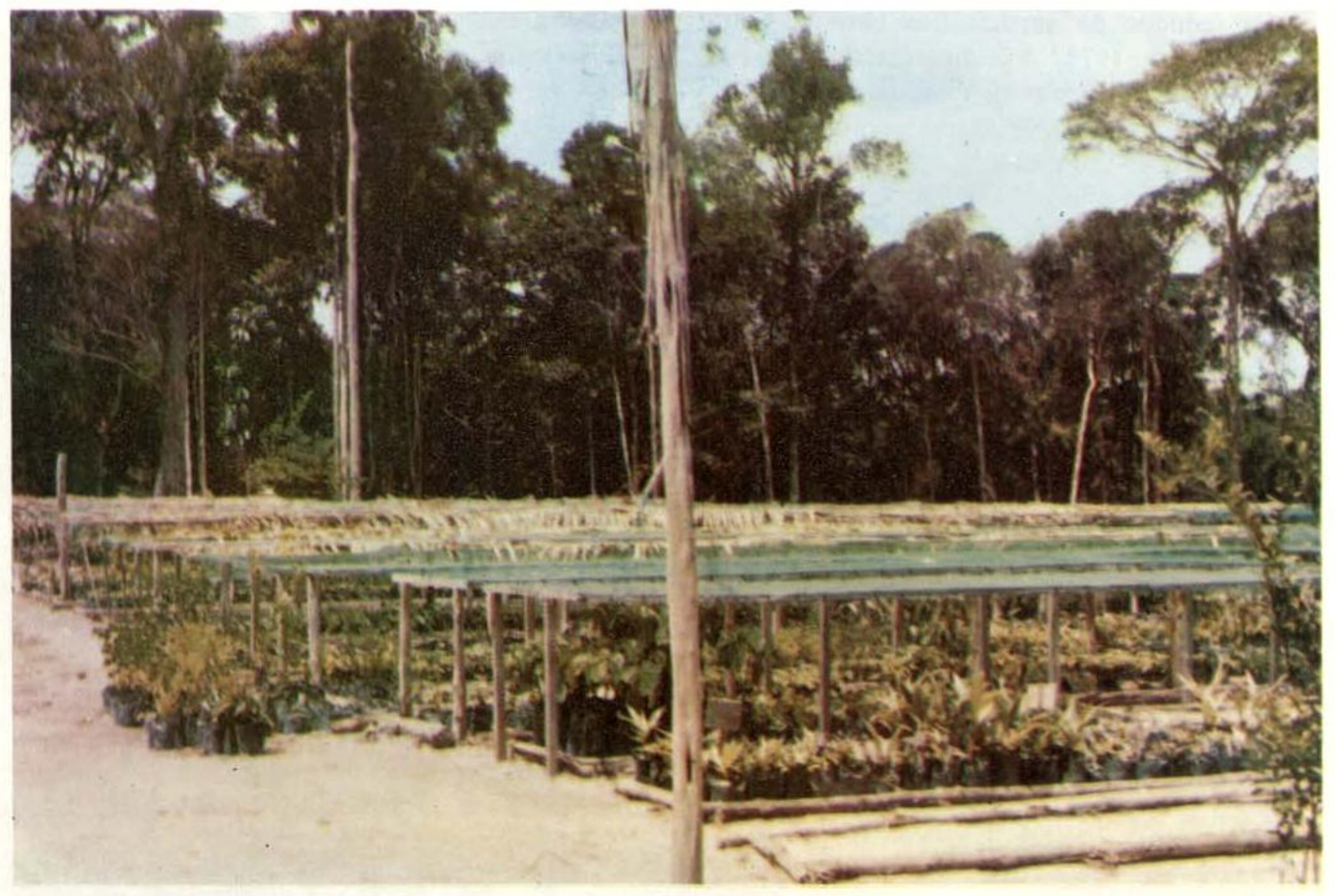

Fig. 2 - Viveiro Florestal na Estaçäo Experimental de Silvicultura Tropical (EEST).

Desse experimento foram coletadas informações para 5 publicações (Vieira, 1970; Volpato et al., 1972; Volpato et al., 1973; Alencar \& Fernandes, 1978 e Alencar \& Araujo, 1978).

Atualmente esse experimento está sendo mantido e conservado pela Divisão de Reflorestamento do Departamento e as medições continuam sendo feitas anualmente.

Em janeiro de 1965 começou-se a marcação, mapeamento e identificação botânica de espécies florestais para estudos fenológicos, sendo que as primeiras observações foram feltas logo em seguida. Do projeto original foram tomadas 100 espécies florestais diferentes, 3 árwores de cada uma. As observações são feitas durante todo o ano, desde a implantação. Das informações obtidas foram publicados 2 trabalhos científicos (Araujo, 1970 e Alencar et al., 1979) .

Com a crescente valorização de algumas espécies florestais, foi também necessário iniciar estudos fenológicos específicos para es- pécies como Aniba duckei Kostermanns (Paurosa) e Copaifera multijuga Hayne (Copaíba), respectivamente em 1966 e 1980. Para o estudo de fenologia do Pau-rosa foram marcadas 20 árvores para serem observadas e para a da Copaíba, 82 árvores. As observações são feitas anualmente durante o ano todo, pela equipe de Fenologia da Divisão de Floresta Natural do Departamento de Silvicultura Tropical. Por enquanto só um trabalho científico foi publicado (Magalhães \& Alencar 1979).

Em Fenologia também, em 1978, foram iniciadas as observações para estudos fenológicos de Palmeiras. Conforme o projeto original foram tomadas 19 diferentes espécies de Palmeira com um número variável de cada. Apesar do grande interesse sobre essas espécies. ainda não foram identificadas botanicamente não tendo, por esta razão, produzido nenhum trabalho científico para publicação. As observações programadas no projeto original estão sendo feitas normalmente pela mesma equipe de outros estudos fenológicos. 
Os estudos de associações botânicas iniciaram-se em 1976. Inicialmente foi tomado para estudos o Pau-rosa (Aniba duckei Kostermanns) com os objetivos de caracterizar as comunidades dessa espécie florestal, a formação das associações, a distribuição dos grupos numa determinada área e a freqüência de outras espécies ao redor da espécie em estudo. Esse estudo está sendo desenvolvido em 2 diferentes tipos de solo, arenoso e argiloso e conduzido pelo Assistente de Pesquisas Jurandyr da Cruz Alencar de onde, provavelmente, será tirada a sua tese de doutoramento.

Em janeiro de 1979, o Assistente de Pesquisas Luís Mauro Sampaio Magalhães implantou o projeto referente a estudos fisiológicos de essência florestais. Nesse trabalho estão sendo estudadas 6 diferentes espécies, naturais e plantadas, de floresta tropical de terra firme e as adaptadas às condições impostas. As espécies naturais são Dypterix odorata (Cumaru) e Scleronema micranthum (Cardeiro) e as plantadas, Cedrelinga catenaeformis
(Cedrorana), Carapa guianensis (Andiroba), Eucalyptus deglupta e Gmelina arborea. Os objetivos desse trabalho de pesquisa são: estudar o enraizamento de essências florestais em plantios experimentais nas fases de viveiro e de campo, correlacionar este enraizamento com condições de solo e luminosidade como também o crescimento aéreo da planta, determinar as adaptações dos sistemas radiculares às diferentes condições de luminosidade e de solo e, se possível, comparar com as mesmas espécies em condições naturais. Desse trabaIho, provavelmente, sairá a tese de mestrado do referido pesquisador. O delineamento estatístico para este experimento foi definido como fatorial para possibilitar a ava!iação dos efeitos de adubação e luminosidade sobre o desenvolvimento radicular das espécies florestais estudadas.

Com a crescente preocupação com problemas referentes às fontes alternativas de ener. gia, o Departamento, através do Assistente de Pesquisas Jurandyr da Cruz Alencar iniciou

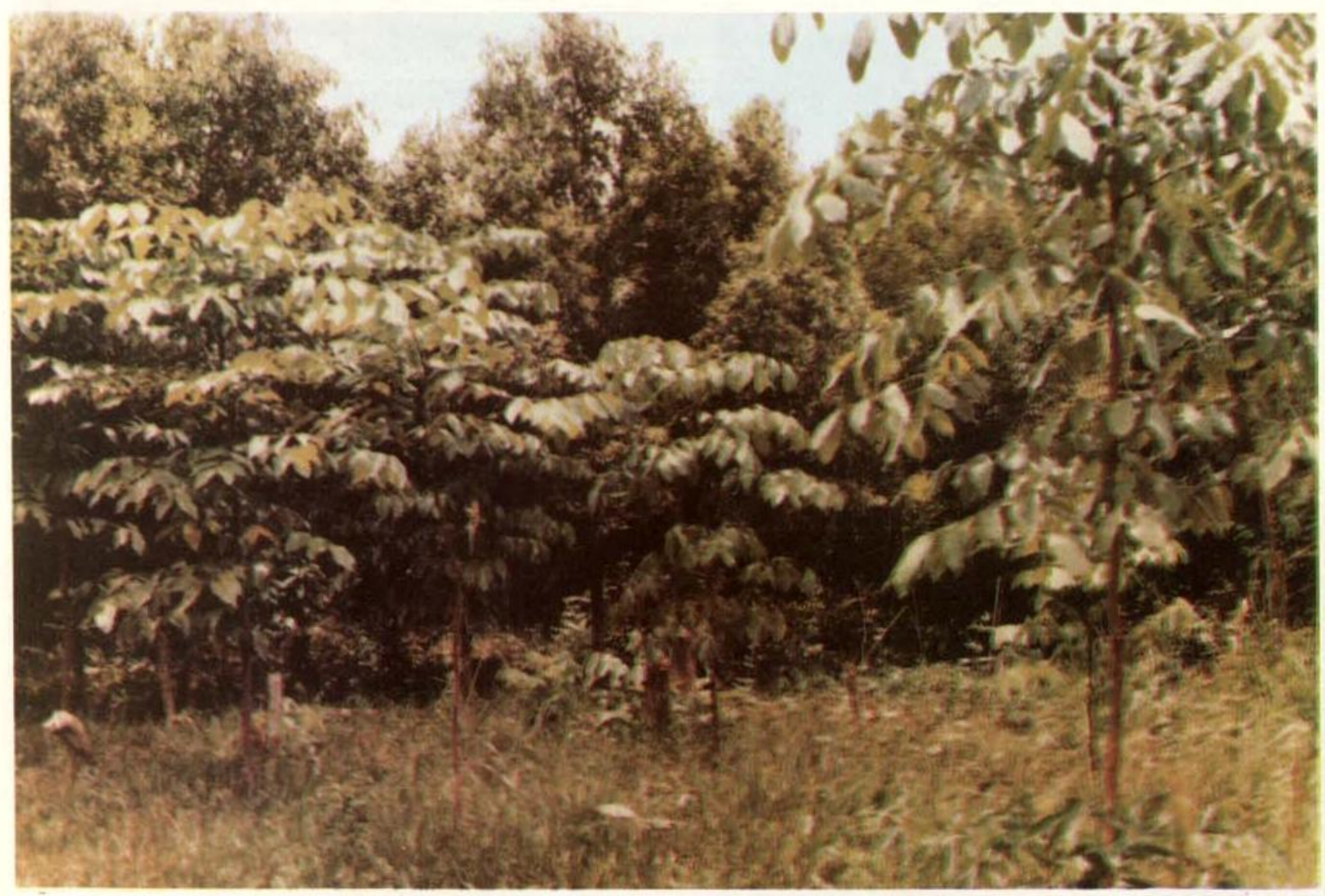

Fig. 3 - Plantio de Cedrelinga catenaeformis e ao fundo Eucalyptus deglupta na EEST com 1 ano de idade. 


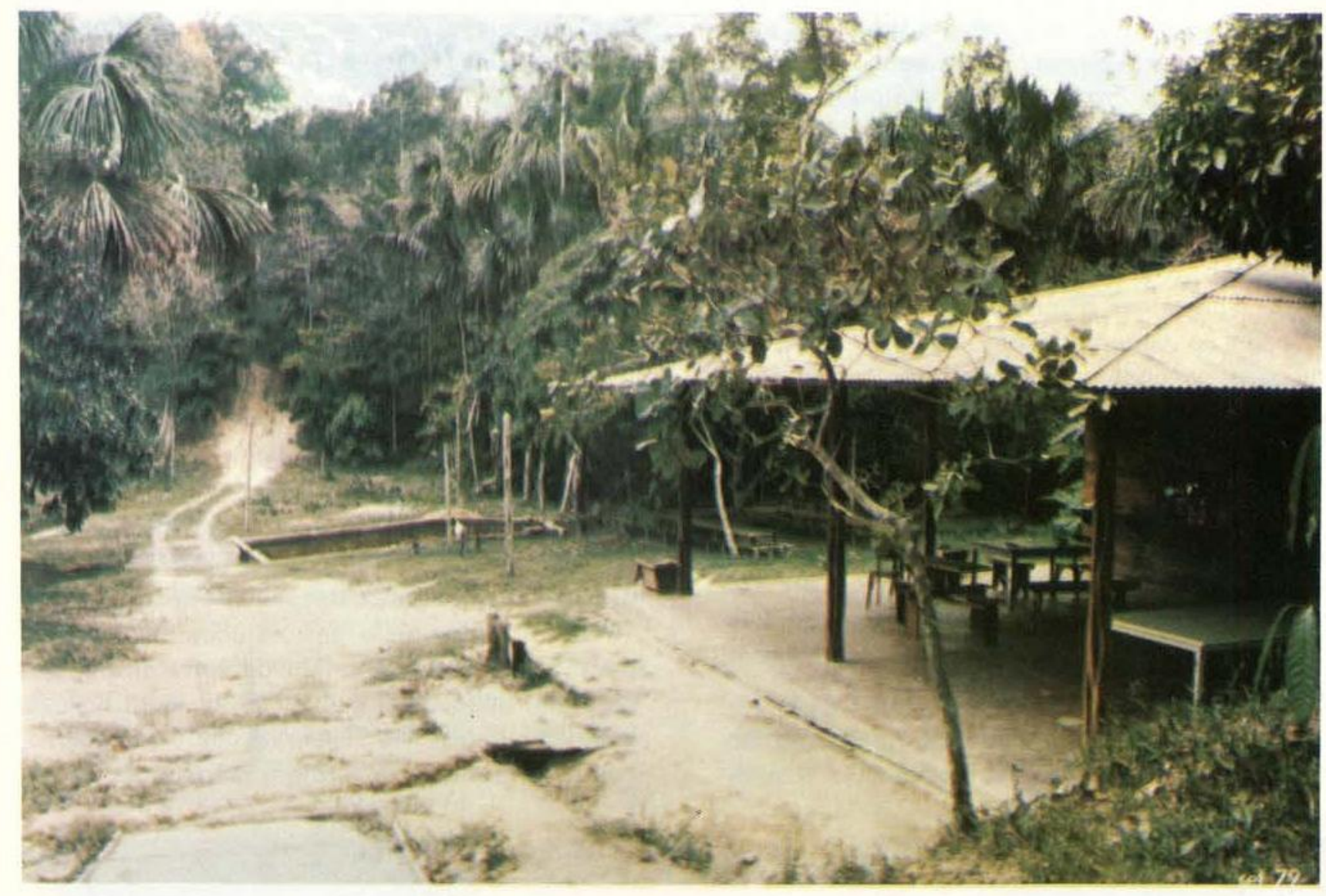

Fig. 4-Vista da cantina dos trabalhadores da Reserva Ducke.

em 1980 o estudo sobre a produção de óleos essenciais da Copaifera multijuga Hayne (Copaíba). Os objetivos desse estudo são: determinar a época ideal para a coleta do óleo, determinar a produção anual média por árvore e viabilidade de explorá-la comercialmente para fins energéticos, estudar a influência genética sobre a produção, caracterizar a sua composição química e fazer estudos com equações de regressão para a produção em função de variáveis independentes como diâmetro de copa. diâmetro à altura do peito (DAP) e altura total da árvore. Para este estudo estão sendo observadas, depois de perfuradas, 82 árvores de Copaíba com DAP maior que $35 \mathrm{~cm}$. e o óleo está sendo extraído duas vezes por ano. Por enquanto nenhum trabalho científico foi publicado devido a insuficiência de dados, em relação a tempo, para o estabelecimento de equação de regressão e estudos de correlação linear.
Mais recentemente, no início de 1981, foi começado a seleção de árvores porta-sementes a partir de informações do calendário anual das espécies florestais fornecido pela Fenologia. Estão sendo selecionadas as espécies com aproveitamento industrial comprovado para futuros reflorestamentos ou recuperação de áreas degradadas. Os objetivos dessa seleção são: obter e manter árvores porta-sementes com características fenológicas conhecidas, garantir a propagação e melhoramento de indivíduos selecionados naturalmente na floresta e racionalizar a coleta de sementes de espécies selecionadas. Este trabalho, além de suprir com sementes o Departamento, permitirá ainda delinear pesquisas concernentes a coleta e armazenamento de sementes. O responsável por esse projeto é o Assistente de Pesquisas Antenor Pereira Barbosa.

Sobre melhoramento florestal, também no início de 1981, foi implantado o projeto de pes- 
quisa sobre a determinação do método de propagação vegetativa de espécies florestais amazônicas de terra firme. Estão sendo utilizadas a Estaquia e a Enxertia como métodos de propagação. Para a interpretação estatística dos resultados serão utilizados os princípios do delineamento inteiramente casualizado, conforme o modelo proposto no projeto e implantado no campo. Os objetivos desses experimentos são: determinar o método mais adequado de propagação vegetativa em espécies florestais valiosas visando obter árvores melhoradas, permitir a manutenção e o uso do potencial genético desenyolvido por essas espécies ao longo de várias gerações em florestas naturais e facilitar a propagação de espécies de difícil germinação via sementes ou aquelas que apresentam problemas de produção e/ou armazenamento de sementes. O Assistente de Pesquisas Benedito Vastano Jr. é o responsável por esse projeto.

Mesmo em se tratando de pesquisas florestais, também é possível conseguir resulta- dos conclusivos em curto prazo, como é o caso das pesquisas com germinação de sementes realizadas na Reserva Ducke. Já publicados, Araujo (1967), Araujo (1970), Araujo et al. (1971) e Magalhães \& Alencar (1979). Em termos de sementes, o objetivo do Departamento é conhecer tudo sobre germinação de todas as espécies florestais de interesse econômico para a região amazônica, como também, as promissoras.

\section{ESTAÇÃO EXPERIMENTAL DE SILVICULTURA TROPICAL (EEST)}

Com a nova política de utilização da Reserva Ducke todas as pesquisas que envolvem plantios ou derrubadas de árvores foram transferidas para a EEST e, logo no primeiro ano de utilização da nova estação de pesquisa, em 1972, foi dado início aos estudos fenológicos de 100 espécies florestais de terra firme, depois de marcadas, mapeadas e identificadas botanicamente. As observações, de acordo com a orientação do projeto, são feitas anual-

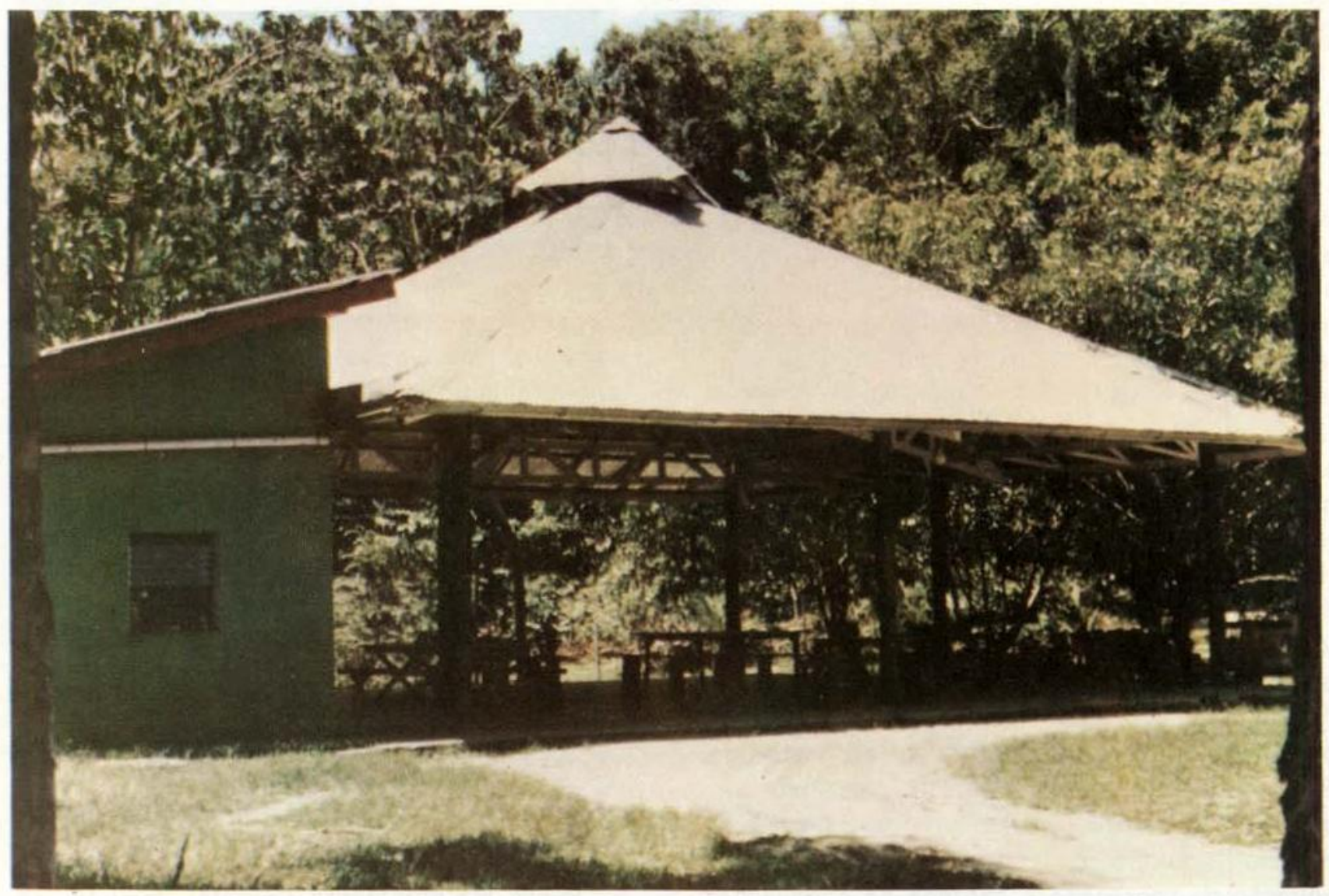

Fig. 5 - Vista da cantina dos trabalhadores da EEST. 
mente ćurante todo o tempo em 5 árvores de cada espécie. Ainda não íoi publicado nenhum trabalho científico. Em agosto de 1976 iniciaram-se as observaçôes para a Fenologia das espécies florestais de Campina da Reserva Biológica de Campina, incluída administrativamente à EEST. A metodologia utilizada nesse trabalho é a mesma dos outros estudos fenológicos e, por enquanto, a única coisa que se faz é a observação reguiar, sempre associando com os dados meteorológicos.

Também no primeiro ano de implantação da EEST foram feitos plantios na área da estação. Como linhas de enriquecimento da floresta natural foram plantadas a Carapa guianensis (Andiroba) e a Cedrelinga catenaeformis (Cedrorana). Essas linhas são conservadás adequadamente mas, mesmo assim, ainda não se tem informações suficientes para concluir sobre o comportamento dessas espécies como forma de enriquecimento. Para o ensaio de espécies em plena abertura foram utilizadas 13 diferentes espécies florestais, nativas e exóticas, sendo que, neste momento, vale ressaltar o comportamento de somente 2 espécies, Nauclea diderichii (Belinga) e Jacaranda paraensis (Caroba).

Em 1978, o Assistente de Pesquisas Noeli Paulo Fernandes, reiniciou os trabalhos com ensaios de espécies plantando 2 procedências de Eucalyptus deglupta, 2 procedências de Eucalyptus robusta, Eucalyptus tereticornis, Gmelina arborea e duas espécies nativas, Carapa guianensis (Andiroba) e Cedrelinga catenaeformis (Cedrorana). Esses plantios foram feitos em escala piloto, sendo plantadas 16 árvores de cada espécie com 3 repetições e mantidos de acordo com orientações contidas no projeto original. O objetivo principal desse experimento é descobrir as espécies mais adequadas para futuros reflorestamentos em plena abertura, em condições amazônicas.

Continuando ainda com pesquisas de regeneração artificial, em maio de 1980 foi implantado um povoameno de Copaifera multijuga Hayne (Copaíba), com mudas de árvores de alta produção e de baixa produção de óleo. para comprovação da influência genética na produção. Em maio do mesmo ano foi implantado o projeto de pesquisa com 3 diferentes espacamentos ( $2 \times 3,3 \times 4$ e $4 \times 4.5$ metros $)$ para as seguintes espécies florestais: Schefflera mcrototoni (Morototó), Jacaranda paraensis (Carcba) e Cedrelinga catenaeformis (Cedrorana) .

E, finalmente, em 1980 também, deu-se inicio a implantação do subprojeto Ecologia e Manejo Florestal do projeto Manejo Ecológico e Exploração da Floresta Tropical úmida de terra firme, Convênio 530/CT e 531/CT, BID/ FNDCT. Este subprojeto tem por objetivo principal a determinação do nível de corte, ideal para a exploração da floresta tropical de terra firme, que forneça o máximo de rendimento com um menor impacto ambiental. O povoamento remanescente, após a exploração, será conduzido silviculturalmente e nele se fará estudos acompanhativos da regeneração natural, visando a determinação do crescimento e incremento para se poder planejar uma futura produção madeireira auto sustentada. Na mesma área serão feitos ainda estudos com regeneração artificial e enriquecimento da floresta natural.

Neste momento todos os 3 blocos, de 24 hectares cada, para estudos de regeneração natural estão marcados, subdivididos em 6 subbiocos (tratamentos silviculturais) e inventariados a $100 \%$ das árvores com DAP maior que $25 \mathrm{~cm}$. Aproveitando o Inventário Florestal a $100 \%$ das espécies comercializáveis está sendo feito a pesquisa sobre a determinação do tamanho ideal de parcelas para Inventários no Distrito Agropecuário da SUFRAMA. Esta pesquisa já está na fase de conclusão e está sob a responsabilidade do Pesquisador Assistente Niro Higuchi e dos Assistentes de Pesquisas Fernando Cristovam da Silva Jardim e Joaquim dos Santos. O Inventário da regeneração natural está na fase de definição de metodologia e será iniciado ainda este ano. Devido a vários fatores a exploração florestal será executada somente no próximo ano, em 1982, e depois disso serão feitos novamente os Inventários das comerciais e da regeneração natural para a primeira avaliação dos efeitos da exploração, do ponto de vista silvicultural. Os estudos com regeneração artificial serão feitos numa área de aproximadamente 50 hectares, explorada em corte raso e, o enriquecimento, num bloco de 24 hectares, explorado comercialmente num só nível de corte. 


\section{COMENTÁRIOS}

Ensaios de espécies na Reserva Florestal Ducke:

Espécie

Clarisia racemosa (Guariuba)

Carapa guianensis (Andiroba)

Mezilaurus itauba (Itauba)

Cedrela odorata (Cedro)

Caryocar villosum (Piquiá)

Jacaranda paraensis (Caroba)

Andira parviflora (Sucupira)

Goupia glabra (Cupiuba)

Aniba canelilla (Preciosa)

Tabebuia serratifolia (Pau d'arco)

Bagassa guianensis (Tatajuba)

Aniba duckei (Pau rosa)

Cedrelinga catenaeformis (Cedrorana)

Pithecolobium racemosum (Angelim rajado)

Dipteryx odorata (Cumaru)

Ocotea rubra (Louro gamela)

Copaifera multijuga (Copaiba)

Scleronema micranthum (Cardeiro)

Callophyllum angulare (Jacareuba)
$\operatorname{DAP}(\mathrm{cm})$

$\begin{array}{rrr}19.5 & 1.75 & 27 \\ 20.7 & 5.47 & 100 \\ 9.5 & 4.84 & 60 \\ 7.4 & 4.75 & 67 \\ 12.4 & 7.98 & 40 \\ 19.7 & 6.88 & 80 \\ 6.7 & 2.19 & 60 \\ 20.8 & 5.64 & 60 \\ 8.0 & 3.61 & 67 \\ 5.1 & 3.73 & 93 \\ 21.3 & 10.96 & 67 \\ 10.2 & 4.95 & 100 \\ 26.4 & 9.86 & 67 \\ 10.9 & 3.65 & 73 \\ 12.2 & 6.82 & 67 \\ 8.4 & 3.95 & 87 \\ 9.7 & 4.71 & 60 \\ 13.7 & 8.39 & 73 \\ 15.4 & 8.88 & 33\end{array}$

DAP: Diâmetro médio à altura do peito, a $1,30 \mathrm{~m}$ do solo HC: Altura comercial, medida na primeira inserção significativa de galhos

S\%: Percentagem de sobrevivência

Todos esses plantios foram levados a cabo entre 1963 e 1964, em linhas alternadas contendo 15 árvores cada uma e em plena abertura do dossel.

Apesar do tamanho das parcelas experimentais e da falta de repetições, o ensaio de espécies apresentado no quadro acima se trata do experimento mais antigo no Amazonas com regeneração artificial de espécies nativas. Sendo assim, essas informações são valiosas como ensaio de eliminação de espécies, fato comprovado nos plantios feitos na Estação Experimental de Silvicultura Tropical (EEST) com a maioria dessas espécies, a partir de 1972 . Até o momento tem sido obtida a mesma tendência de crescimento dessas espécies na EEST.

Para o projeto Manejo Ecológico e Exploração da Floresta Tropical Úmida, no tocante à
Regeneração artificial, os plantios serão feitos de acordo com as potencialidades de determinadas espécies já comprovadas nos ensaios da Reserva Florestal Ducke e na EEST.

Quanto a plantios sob sombra, os ensaios implantados na Reserva Ducke em 1963/1964 tem agora condições de, pelo menos, fornecer bons indicativos para novos ensaios desse tipo, apesar da falta de um embasamento maior de estatística durante a implantação dos mesmos. Para o projeto de Manejo Ecológico, por exemplo, a Carapa guianensis (Andiroba) e a Cedrelinga catenaeformis (Cedrorana) serão utilizadas como espécies com potencialidade comprovada.

Dos estudos fenológicos tem-se documentado o comportamento quanto a floração, frutificação e mudança foliar das seguintes espécies florestais : 
Virola michelii (Ucuuba preta)

Vouacapoua pallidior (Acapu)

Erisma fuscum (Quarubarana)

Mezilaurus synandra (Itaúba folha fina)

Nectandra rubra (Louro gamela)

Jacaranda paraensis (Caroba)

Hevea guianensis (Seringa vermelha)

Platymiscium duckei (Macacaúba)

Dipteryx odorata (Cumaru)

Dinizia excelsa (Angelim pedra)

Couma macrocarpa (Sorva grande)

Calophyllum angulare (Jacareúba)

Andira unifoliolata (Sucupira chorona)

Aniba canelilla (Casca preciosa)

Goupia glabra (Cupiuba)

Osteophoeum plastyspermum (Ucuuba branca)

Copaifera multijuga (Copaíba roxa)

Peltogyne catingae (Violeta)

Peltogyne paniculata (Mulateiro)

Scleronema micranthum (Cardeiro)

Tachigalia paniculata (Tachi preto)

Tabebuia cf. incana (Pau d'arco)

Anacardium spruceanum (Cajuí)

Cariniana micrantha (Castanha de macaco)

Manilkara surinamensis (Maçaranduba)

Cedrelinga catenaeformis (Cedrorana)

Pithecolobium racemosum (Angelim rajado)

Esse trabalho de fenologia, objetivando a construção de um calendário anual das espécies florestais em conjunto com as observações meteorológicas, é resultado de 12 anos de observações na Reserva Ducke.

\section{SUMMARY}

This report shows the evolution of Silviculture, in terms of research, during the 27 years of the existence of INPA (the National Institute for Research in the Amazon), from the first proposal in 1954 by the botanist Adolfo Ducke, to create a forest reserve, now the Ducke Forest Reserve, with also reference to the development of forestry in tropical Brazil.

The silvicultural research tasks developed, and under development, by the Department of Tropical Silviculture, in the Ducke Forest Reserve (Km-26 along the Manaus-Itacoatiara Highway of 10,000 hectares), and in the Experimental Station of Tropical Silviculture (Km-45 along the Manaus-Caracaraí highway of 21,000 hectares), are briefly summarised. Regarding the tasks under development at this moment, the Project "Ecological Management and Exploitation of Moist Tropical Forest", in the Agriculture and Animal Husbandry District of SUFRAMA (Superintendency of the Free Zone of Ma- naus), starting at $\mathrm{Km}-14$ along the access road $\mathrm{ZF}-2$, has priority, with special emphasis on natural Regeneration.

The report lists some conclusive results of the silvicultural works carried out at the field research stations of INPA.

\section{REFERENCIAS BIBLIOGRAFICAS}

ALENCAR, J.C. \& ARAUJO, V.C.

1980 - Comportamento de espécies florestais ama. zônicas quanto à luminosidade. Acta Ama. zonica, 10 (3): 435-444.

ALENCAR, J.C. \& FERNANDES, N.P.

1978 - Desenvolvimento de árvores nativas em ensaios de espécies. I - Pau-rosa (Aniba duckei Kostermanns) Acta Amazônica, 8 (4): 523-541.

ALENCAR, J.C.; ALMEIDA, R.A.; FERNANDES, N.P. 1979 - Fenologia de espécies florestais tropical úmida de terra firme na Amazônia Central. Acta Amazonica, 9 (1): 163-198.

ARAUJO, V.C.

1967 - Sobre a germinação de Aniba (Lauraceae) 1 - Aniba duckei Kostermanns (Pau-rosa itauba). INPA, Bot., (23), 14 p.

1970a- Fenologia de essências florestais amazônicas. I - Boletim do INPA (4), 25 p.

1970b- Sobre a germinação de Aniba (Lauraceae). II - Aniba canelilla (H.B.K.) Mez Casca preciosa - INPA, Bot., (12), 9 p.

ARAUJA, V.C. et all.

1971 - Sobre a germinação do Mogno (Aguano) Swietenia macrophylla King. Acta Amazon:ca, 1 (3): 59-69.

MAGALHÃES, L.M.S. \& ALENCAR, J.C.

1979a - Fenologia do Pau-rosa (Aniba duckei Kostermanns); Lauraceae, em floresta primária na Amazônia Central. Acta Amazonica, 9 (2): 227-232.

1979b- Poder germinativo de sementes de doze espécies florestais da regiâo de Manaus. Acta Amazonica, 9 (3): 411-418.

VIEIRA, A.N.

1970 - Aspectos silviculturais do Pau-rosa (Aniba duckei Kostermanns). I - Estudos preliminares sobre o incremento volumétrico. Bo. letim do INPA (14), $15 \mathrm{p}$.

VOLPATO, E.; SCHMIDT, P.B.; ARAUJO, V.C.

1972 - Carapa guianensis Aubl. (Andiroba). Estudos comparativos de tratamentos silviculturais. Acta Amazonica, 2 (3): 75-81.

1973 - Situação dos plantios experimentais na Reserva Ducke. (Acta Amazonica, 3 (1): 71-82. 